\title{
Coaching using a Psychodynamic Approach
}

By Dr. Nursel Aydintug Myrvang

Biruni University

Abstract- This paper summarises some of my experiences, observations and reflections over more than 30 years in the management of private companies, universities and hospitals, on how to deal with anxieties both in individuals but also in groups. To me the factors required to build and maintain a happy organization, is to understand the people working there, and appreciate the complexity of human behavior both on a conscious and unconscious level.

I have suggested that coaching using a psychodynamic approach may be a tool in measuring the health of an organization and reducing anxieties and at the same time giving the participants on a 'coaching journey', a better understanding of themselves. However, to get positive results from the 'coaching journey' the coach, but also managers, should have an understanding of elements such as: listening, mentalising, empathy, transference, counter transference, intuition and neuroscience.

Keywords: the happy organization, human behavior, selfawareness, psychodynamic coaching approach.

GJHSS-H Classification: FOR Code: 170199

Strictly as per the compliance and regulations of:

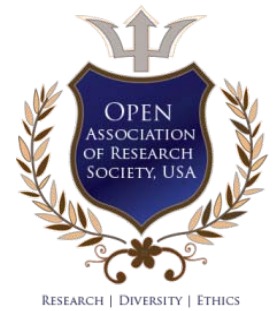

(C) 2019. Dr. Nursel Aydintug Myrvang. This is a research/review paper, distributed under the terms of the Creative Commons Attribution-Noncommercial 3.0 Unported License http://creativecommons.org/licenses/by-nc/3.0/), permitting all non-commercial use, distribution, and reproduction in any medium, provided the original work is properly cited. 


\title{
Coaching using a Psychodynamic Approach
}

\author{
Dr. Nursel Aydintug Myrvang
}

Abstract- This paper summarises some of my experiences, observations and reflections over more than 30 years in the management of private companies, universities and hospitals, on how to deal with anxieties both in individuals but also in groups. To me the factors required to build and maintain a happy organization, is to understand the people working there, and appreciate the complexity of human behavior both on a conscious and unconscious level.

I have suggested that coaching using a psychodynamic approach may be a tool in measuring the health of an organization and reducing anxieties and at the same time giving the participants on a 'coaching journey', a better understanding of themselves. However, to get positive results from the 'coaching journey' the coach, but also managers, should have an understanding of elements such as: listening, mentalising, empathy, transference, countertransference, intuition and neuroscience.

Thus understanding and accommodating the complexity of human behaviours and having the tools to mitigate anxieties, will be a good foundation for building a happy and prosperous organization, and reducing unnecessary change processes.

Keywords: the happy organization, human behavior, selfawareness, psychodynamic coaching approach.

\section{InTRODUCTION}

A II organizations and their workers will have anxieties as a result of internal and external forces. The leaders need to know how to handle these anxieties and make adjustments, and in a fastchanging world this will require frequent updates on the health of the organization.

Hospitals are no different to any other business entity, but a good example of a place where anxieties play a role in the daily activities. Hospitals' main aim is to take care of the physical need of the patients but also help patients and relatives to manage the stress associated with illness, death and psychological disturbances. In order for nurses to provide appropriate care they need the support of a management structure that understands their work and can create the environment to reduce their anxieties. Armstrong and Rustin (2015).

However, even though there have been developments in the processes of supporting the patient's psychological and emotional recovery, the staff is expected to get on with it and expect little help and support. Evans (2014), Tutton and Lang staff (2015)

To give support and help to nurses and the management working in the health sector, I suggest that coaching using a psychodynamic approach, should be

Author: Biruni University. e-mail: nurselaydintug@gmail.com carried out with individuals, groups of nurses and the managers. By using this approach there will be the possibility to detect the underlying currents flowing through the organization and to pinpoint the real problems affecting the staff, groups and managers. Thus avoiding a change process that neglects the human factor and uses bureaucratic procedures and documents to obscure personal and organizational that creates new anxieties.

\section{a) The Human Factor}

However, before starting on any changes and reorganizations, we need to recognize that the first step in creating and maintaining a healthy organization in a fast-changing world, is for all of us to understand, appreciate and accept the complexity of human behaviours.

We need to appreciate that men and women are not robots, but that people have many wishes, fantasies, problems, defensive behaviours and anxieties - some are conscious and some unconscious.

Kets de Vries (2011).

Hence to understand people's behaviors in groups and organizations, we need to draw on knowledge from areas such as psychoanalyses, psychotherapy and dynamic psychiatry. Having this knowledge and accepting and exploring the hidden unconscious processes that affect human behavior, may give us a better understanding of the complexities of groups and organizational life. Kets de Vries and Cheak (2014).

\section{b) Coaching and Therapy}

Coaching using a psychodynamic approach will draw heavily on psychotherapy processes and skills. Both coaching and therapy work with behavior, emotion and perception. Hence to get results, the coach or therapist will need to establish a meaningful relationship with the client.

In therapy, the main aim is to reduce the behavior symptom and character problems and the interaction is more of a passive and reflecting nature.

The coach, however, needs to have a broader perspective and knowledge of organizational structures, management, leadership, corporate structures and economics and in addition knowledge from the psychodynamic framework. Kets de Vries et. al (2007).

c) History

Freud's psychoanalytical theories of human behavior are the first element in the psychodynamic 
framework, which has been extended to include work by Adler (1927), Jung (1964) and Erikson (1950). McLeod (2007).

The application of the psychodynamic approach has accelerated after the second world war by organisations such as the Tavistock Institution in the UK, the Menninger Clinic and Boston Psychoanalytic Institution in the USA. Miller (1995), Fraher (2004), Zaleznik (1966), Levison (1972).

They argued that by using psychoanalytical tools from the psychodynamic framework, they could identify irrational processes influencing leaders and followers in a decision making event.

The psychodynamic approach was initially mainly used to understand processes in public organisations, but was taken up by more and more business entities, and a forum for interested parties working in this field "the International Society for the Psychoanalytical Study of Organisations (ISPSO)", was established in 1983. (www.ispso.org).

The elements in the psychodynamic approach are increasing at an accelerating rate and sophistication and incorporate finding from areas such as ethology, anthropology and neuroscience.

\section{d) Assumptions}

The application of a psychodynamic approach defines the following assumptions for a coaching process (Kets de Vries and Korotov (2007):

- our unconscious play will have a powerful effect on our actions, thoughts, fantasies, hopes and fears,

- our behavior and feelings as adults are rooted in our childhood experiences (we are all products of our past),

- all human behavior has a rational explanation (usually unconscious),

- emotion is the main contributor to our identity and behavior.

\section{The CoAching Journey}

To achieve success as a manager, you most likely will have to create groups that have the right mixture of authenticity, significance, excitement and community, but also manage to have fun and enjoy the work.

\section{a) Framework}

The motivation for starting on a coaching journey may be defined as given by Kimsey-House et al (2011)," to satisfy the client's desire for fulfilment, balance and process". I like a slightly simpler definition by saying my aim is to make people a "little happier". I know that people suggest that happiness is too superficial and that one should aim for containment or satisfaction.

In my world happiness is a combination of things such as self-awareness, trust, success and to mix these with daily spices to make a happy life. Happiness should further be looked upon as a journey as described by Kets de Vries (2000): "Finding happiness isn't like arriving at a station. We don't one day get to a certain place where we are flooded with happiness. No miracles happen when we arrive at the final destination. There is no final destination. There will always be a next stop. Happiness is the way in how we travel. It is important, then, that we focus more on the rout, the scenery, and our fellow travellers than on the destination. We need to try to grasp happiness on the way, enjoying the journey rather than impatiently counting the kilometres."

Schopenhauer in the Triplet of Essays: What a Man Is, What a Man Has, What a Man Represents, emphasises that it is only what an individual is that counts; neither wealth nor goods nor social status nor good reputation results in happiness.

A possible way of "testing" how you are really living may be found in Nietzsche's Thus Sprake Zarathustra, where the aged prophet Zarathustra poses a challenge; "What if you were to live the identical life again and again throughout eternity- how would that change you?" This thought may increase your awareness that this life, your only life, should be lived well and fully, and accumulating as few regrets as possible.

\section{b) Steps in the Coaching Journey}

Before starting on the journey we need to have in our mind the following words by Kimsey-House et al (2011); "we believe that coaching is mainly about discovering, awareness and choice. It is a way of effectively empowering people to find their own answers, encouraging and supporting them in the path as they continue to make important life-giving and life-changing choices".

So to me coaching is a journey where the coach and coachee are equals but where the coach is the 'service provider' and 'energy supply' for the coachee, to reach his desired goals.

The journey will be designed as unique for each and every case, and designed round the following steps;

1. Define and agree the contract and including confidentially conditions.

2. Establish who we are and where we are.

3. Define initial goals and expectations. Make provisions for changes during the journey and that the goal might be a moving target.

4. Set out the journey with and provide stops for evaluating new 'learning' events.

5. Agree that we are at the end of the Journey and close the case with the coachee.

6. Summarise the learning from this journey. 
The journey may start in a comfortable office with a cup of coffee or tea and after agreed on step 1, 2 and 3, it's off and out ready to start navigating towards the goal. However, to get to the target we will have to cross open planes, dense forests where it may be difficult to see the stars or sun, making it difficult to find the way, or there might be foggy situations where difficult and risky decisions may have to be made, to take the next steps.

Further on our may to cross deserts there might be difficult situations, and we may have to suffer, before we find the best way to reach the target. In such situations there might be "easy" to decide to take a detour and get back to familiar territory. In situations like this we need to keep focused on the target and the way in front of us, and use what we have learned, and build on that to find the best possible way forward.

When reaching the target and the coachee has reached the goal, it's time to celebrate.

In reaching the target and to be able to celebrate the success, it is important that the coach and coachee have been able to speak the truth, but most of all they have been able to build trust.

There will be no success without trust and building, developing and maintain trust is the main ingredient of a happy life. Unfortunately, trust-building is not easy for highly competitive people in today's society. In many organisations or entities, trust is a very rare commodity. Relationships of trust depend on our willingness to look not only to our own interest, but also to the interest of others. For trust to exist we need to deal with such complicated issues as openness, honesty, active listening, communication, consistency, competence, fairness and mutual respect. Trust is a delicate flower and it does not take much to crush it, and once destroyed it takes a very long time to nurture it back into bloom.

Further, in building trust in ourselves and in others we need to be authentic. "If we are not honest with ourselves, how can we possibly be honest with others?"

The most difficult element for the coachee trying to reach the target and the goal, is the willingness to change. As the saying goes, "To change your behavior is easier than changing your perceptions." Behavior can be compared to being on a stage where you play different roles, and as such can be thought. Changing your perceptions may be more difficult and I believe that this is not possible without "finding yourself". Selfawareness is an important factor in building self-esteem and confidence. Self-awareness helps us to understand what drives us, what turns us off, what makes us happy, and what we are passionate about. It helps us clarify what we need to do to improve ourselves as a person.
Unfortunately, the road to self-awareness is not easy. As Leo Tolstoy once wrote "Everyone thinks of changing the world, but no one thinks of changing himself."

Being human, we will resist some of the observations from those helping us, work towards change but we will have to work through that resistance. As we work through our resistance and make the unconscious conscious, we take decision-making control back into our own hands.

For me, as a coach, I will need to practice selfmanagement and resist personal opinions. However, a coaching journeys will give me the opportunity to learn and find myself. I have for some time worked on a process of understanding myself and realized that I have to go into my earlier life. I am looking at myself as a "Russian doll" with many dolls of different sizes. Each doll is for me defined by a special event or time in my life when important events took place, and hence they are parts of defining who I am today. I am pleased to find out that the "Russian doll" model is compatible with the Freud (1905) and Erikson (1950) Life Cycle Model.

\section{Coaching Model}

At the moment, I see my model as a rucksack with important elements in it, and which I can use where and when required on my journey with the coachee. The elements in my rucksack will be listening, mental sing, empathy, transference, counter-transference, intuition and our plastic brain. I do, however, over time expect to add new or modify existing elements as learning is a continuous process.

\section{a) Listening}

"Listening is not done by the ears, but by the mind. We hear sounds, but we listen to meanings;"W. Meissner.

I think listening must be one of the first things we do after we are borne, and one of the things we take for granted during our life - this is easy. However, the more you learn and go through life, it dawns on you that listening is more than words and trying to make out what people are saying or meaning to say, can be very difficult. Further, elements such as mode, stress, noise, different cultures, etc. will influence your understanding of what is conveyed and your own response to the other person. In addition, our busy life makes it more and more difficult to have the time to listen.

A listener needs to be sensitive to and capable of processing all kinds of information, originating from various channels, verbal as well as nonverbal. Moreover, the listener must be aware of how his own listening behavior affects the speaker. The speaker and listener engage in a communicative dance. The listener follows and often imitates the body movements of the speaker, and this nonverbal response represents a kind of continuous commentary on what is being said. 


\section{b) Mentalising}

Anybody who is listening carefully to another person is not only receiving information but is also continuously trying to make sense of what is being said. This is influenced by our capacity to understand that behavior is caused by so-called unobservable state of mind, such as wishes, needs, desires, feelings, ideas, hopes, fears, illusions, etc., and to acknowledge that the state of mind of another person may be different from our own. As mentalising is about unobservable states of mind, both our own, and other people the term refers to the capacity to think and make inferences about people and their behaviors.

\section{c) Empathy}

Mentalising is different to empathy as mentalising is a cognitive skill whereas empathizing refers to the capacity to appreciate and understand the feeling of others. Empathy is the ability to subjectively experience the world from another person's perspective. It is not about trying to understand what it would be like for you to be in the other person's shoes, but the ability to experience what it is like for the other person to be in his or her shoes. Empathy is an 'emotional knowing' rather than intellectual understanding. The essential mechanism of empathy is a partial and temporary identification with the other person.

\section{d) Transference and Counter-Transference}

The concept of transference is grounded in observations of how human beings develop and mature. Through interactions with parents, family members, teachers, and other authority figures we encounter, we develop behavior patterns that become the basis for cognitive and effective 'software'. These patterns can be activated by particular cues without our awareness. For example, we meet someone who subconsciously reminds us of a nagging older sister, and we react as if she really were that older sister. More precisely, transference is the process by which one person displaces onto another's thoughts, ideas or fantasies that originated with figures of authority encountered very early in an individual's life. It is a revival or reliving of issues from the past directed towards persons in the present.

Coaches are also human being, and all the above applies to them as well. When forming a relationship with a coachee they need to be aware of counter-transference. This is the situation where the coachee becomes the outlet for the transference of the coach. Coaches need not only to recognize such reactions in themselves, but also to find a way of using this information about their own feelings and reactions to help the coachee become more aware of the types of cues he or she provides to others and the possible responses of people to those cues.

\section{e) Intuition}

I know that I have and are using intuition every day and that it has helped me on many occasions, but I also know that it can give me the wrong picture and not trigger danger signals.

The informative value of intuition was highlighted by Sharp (1937), who stated that, "intuitive knowledge is experienced knowledge, and that the unconscious is a storehouse of experiences which we may have forgotten but have never lost."

My clearest and possibly 'simplest' understanding of intuition came when I read the following definition by Piha (2000), "Intuition is like radar in the front line of our thinking, used to probe and explore preliminary connections with the inner world. Intuition provides immediate views, which are not proper knowledge yet but may be leading to it. As such, intuition allows uncertainty, imprecise boundaries and the dimension of depth in our perceptions. At the same time, intuition is unconditional, like the primary process in general. It does not recognize time, considerations and compromise; a strange immediate impression of certainty often characterizes an intuitive experience."

How do we use intuition in our daily life? Just think of driving your car in a large city. Majority of decisions on how to maneuver and predict what the other drivers are doing, are based on intuition as these moves would not be possible with practical reasoning.

\section{f) Our Plastic and Social Brain}

New research in neuroscience suggest that the plastic and changeable nature of our brains are not passive, though hugely efficient, information processors, but instead are constantly reacting and adjusting according to the vast amount of information that are thrown at us every day. Rippon (2019).

Scientists are just starting to realize that there might be a second 'window of opportunity' to watch the construction and deconstruction of an adult social being. Adolescence marks a period of dynamic reorganization in brain networks. It is a system-level rewiring which sees a shift from local within-system connections to more widespread global connections between different parts of the brain. Blakemore (2018).

According to Lieberman (2013), "we are wired to be social. We are driven by deep motivations to stay connected with friends and family. We are naturally curious about what is going on in the minds of other people. And our identities are formed by the values lent to us from the groups we call our own."

If we think that to understand how we as individual, are interacted with the complex world, then understanding how we interact with other people are far more challenging. We have to cope with our own wants, needs, beliefs and desires and in addition try to predict 
those of other people, often based on some set of mysterious, unspoken rules. We need to use our contact list and sort out our world into the type of people, situations and events that will either good or bad for us, or make us feel good or bad.

Our brain will give a 'like' rating to members of our various groups, encouraging us to seek out and spend time with those members. The brain may, however, rapidly and automatically attach a 'threat alert' to people, who is not part of our social network.

Part of our ability to be social means we have an inbuilt tendency to be biased, both positively and negatively. Adolphs (2003).

\section{LEARNING}

After closing the contract and having said farewell to the client, it is time to see what have I learned from this journey. It may have been a success or a failure. Success is easy but the learning might be limited, as the real learning comes from the ability to see success in failure.

We should keep in mind some wise words from Skovholt (2001),"Practitioners must realize that all our best intentions, all our work, all our competence will sometimes not be enough. We must learn to accept lack of success- that is normative failures- as a component of the work. Being able to come to this realization, accept it and incorporate it into one's professional selfconcept is important for long-term, high quality professional functioning."

Failure is never easy to accept, but it is a missed opportunity, if we do not use it as the basis for learning and personal growth. "By seeing the failure in every success, we remain humble. By seeing the seed of success in every failure, we remain hopeful".

After any contact with a client, we should ask ourselves: How has this client affected me? What does the client really want? Have I been effective or ineffective in helping the client today, and how can I be more effective tomorrow?

\section{Conclusion}

I have outlined why coaching using a psychodynamic approach may be a good tool in decreasing anxieties, and at the same time give me as a coach the opportunity to 'get closer to and find' myself. I have also described how I see the journey with a client, and what building blocks $I$ at the moment see as necessary for doing a good job. I see my coaching model as a rucksack with the building blocks that I have but there is place for new blocks as the learning process progresses.

When I in some years sit down and consider how much success have I had, I like to think that I have had a "rippling effect" on other people. Rippling refer to the fact that each of us creates- often without conscious intent or knowledge- circles of influence that may affect others for years, even for generations. That is, the effect we have on other people is in turn passed on and on to others. It's like throwing a pebble in a pond where the ripples go on and on until they're no longer visible, but continuing at a nano level. Rippling as I use it refers to leaving behind something from your life experience, some piece of wisdom, guidance, virtue or comforts that passes on to others, known or unknown.

Further some wise words from Lao Tzu (600 $\mathrm{BC}$ ) may be used as a guide as I feel that they are appropriate in any discussion or dialog between people:

Learn from people
Plan with the people
Begin with what they have
Build on what they know
When the task is accomplished
The people all remark
We have done it ourselves.

References Références Referencias

1. Adler, A. (1927). "Understanding human nature." Greenburg. USA.

2. Adolphs, R. (2003). "Investigating the Cognitive Neuroscience of Human Social Behaviour." Neuropsychologia 41:2.

3. Armstrong, D, Rustin, M (2015). "Social Defences Against Anxiety." Karnak Books, London.

4. Blakemore, S. J. (2018). "Inventing Ourselves: The Secret Life of the Teenage Brain." Doubleday, London.

5. Erikson, E. H. (1950). "Childhood and society." Norton. New York.

6. Evans, M (2014). "A Response to the Francis Report". Psychoanalytic Psychotherapy. Vol 28. No 2. Taylor \& Francis Ltd.

7. Fraher, A.L (2004). "Systems Psychodynamics: The Formative Years of an Interdisciplinary Field at the Tavistock Institute."History of Psychology.Vol7. No 1.

8. Jung, C. G, et al. (1964). "Man and his Symbols." Anchor Books, New York.

9. Kets de Vries, M. F. R. The Business Graduation Speech: Reflection on Happiness. European Management Journal. June 2000Kets de Vries, M.F.R (2011). "Reflections on Groups and Organizations." Jossey-Bass, USA.

10. Kets de Vrie, M.F.R., Korotov,K, Florent-Treacy,E (2007). "Coach and Couch". Pelgrave Macmillian, USA.

11. Kets de Vries, M.F.R, Cheak, A (2014), "Psychodynamic Approach". SSR Network. Ssr. com/abstract $=2456594$.

12. Kimsey-House, H. et al. (2011). Co-Active Coaching Nicholas Brealey Publication. Boston. 
13. Levinson, H. (1972). "Organizational Diagnosis". Harvard University Press.

14. Lieberman, M.D. (2013). "Social: Why our Brains are Wired to Connect." Oxford University Press.

15. Loo. E. van de (2007). The Art of Listening. Coach and Couch. Palgrave Macmillan.

16. McLeod, S. A (2007). "Psychodynamic Approach." www.simplypsychology.org/psychodynamic.html

17. Miller, W. J (1993).From dependency to autonomy. Studies in organization and change." Free Association Books, London.

18. Piha, H. (2000). Intuition: A Bridge to the Coenes thetic World of Experiences. Finnish Psychoanalytical Society. Rippon, G. (2019). "The Gendered Brain." Penguin Books.

19. Tutton, L, Langstaff, D. (2015). "Reflections on Isabel Menzies Lyth in the light of developments in nursing care". Karnac Books. London.

20. Zaleznik, A. (1966). "Human Dilemmas of Leadership." Harp \& Row. New York 